\title{
Managing nut-induced anaphylaxis: challenges and solutions
}

\author{
This article was published in the following Dove Press journal: \\ Journal of Asthma and Allergy \\ 29 October 2015 \\ Number of times this article has been viewed
}

\author{
Jeanne M Lomas \\ Kirsi M Järvinen \\ Division of Pediatric Allergy and \\ Immunology, University of Rochester \\ School of Medicine and Dentistry, \\ Rochester, NY, USA
}

\begin{abstract}
The prevalence of peanut and tree nut allergy in the USA has increased, especially in the pediatric population. Nut allergy remains the leading cause of fatal anaphylactic reactions. Management of anaphylaxis includes not only treatment of symptoms during a reaction, but strict dietary avoidance and education on potential situations, which may place the patient at high risk for accidental exposure. Cross-reactivity between various nuts along with various cross-contamination sources should be discussed with all nut-allergic individuals. Exciting research continues to emerge on other potential treatments for patients allergic to nuts, including allergen immunotherapy. Results of such interventions have been encouraging, though further studies are needed regarding safety and long-term outcomes before these can be applied to clinical practice.
\end{abstract}

Keywords: peanut, tree nut, anaphylaxis, cross-reactivity, avoidance, immunotherapy

\section{Introduction}

Nuts are consumed by almost $40 \%$ of adult Americans on a given day. ${ }^{1}$ The broad category of "edible nuts" includes both peanuts and other culinary nuts generally referred to as tree nuts. Peanut, commonly in the form of peanut butter, is the most widely consumed edible nut in the USA. Though commonly referred to as nuts, peanuts are actually legumes, which grow underground and share more biologic properties in common with chickpeas, lentils, and beans than other edible nuts. ${ }^{2}$ Tree nuts include other culinary "true" nuts such as chestnuts and hazelnuts, as well as multiple botanical nuts not commonly used in cooking, like acorns. Also included in the tree nut category are drupe seeds, which have a fruit surrounding a stone or pit containing the nut or seed. Drupe seeds include almonds, pistachios, cashews, pecans, and walnuts. Brazil nuts, pine nuts, and Macadamia nuts are also classified as tree nuts but are actually also known as nut-like seeds. ${ }^{3}$ From this point forward, we will refer to tree nuts as an inclusive category of all culinary nuts, excluding peanut.

In a report from the United States Department of Agriculture (USDA) in August 2014, almonds surpassed peanuts as the most widely consumed nut in America (excluding peanut butter), growing in popularity by $>220 \%$ since 2005.4 . An increase in vegetarian and vegan diets, as well as reports on health benefits of nut consumption, attributed to an increase in dietary consumption of nuts. Despite their popularity, nuts are avoided by many Americans due to allergy. An estimated 1\% of the US population has nut (peanut or tree nut) allergy, though the prevalence seems to be growing in children. ${ }^{6,7}$ Although a number of studies have demonstrated successful desensitization to nuts with various forms of immunotherapy, many questions remain unanswered. ${ }^{8}$
Correspondence: Kirsi M Järvinen Division of Pediatric Allergy and Immunology, University of Rochester School of Medicine and Dentistry, 60I Elmwood Avenue, Box 61I, Rochester, NY, USA

Tel +I 5852767295

Fax +| 585276 I 449

Email kirsi_jarvinen-seppo@URMC. rochester.edu 
Oral immunotherapy (OIT), particularly for peanut, has shown promising results, though concerns over safety and long-term effectiveness continue to keep it from mainstream practice in allergy clinics. Currently, the standard of care for patients allergic to nuts is strict dietary avoidance and treatment of anaphylactic episodes with injectable epinephrine. ${ }^{9,10}$ This requires much time in counseling and education of the patient and family, as there are numerous scenarios to which challenges may arise, if not appropriately anticipated.

\section{Clinical presentation}

Peanut and tree nuts are among the most commonly implicated foods in cases of anaphylaxis occurring in both children and adults. ${ }^{11,12}$ Anaphylaxis has been defined as an acute, lifethreatening allergic reaction, involving more than one organ system in the body. ${ }^{13}$ The pathophysiology of anaphylaxis involves release of mediators from mast cells and basophils upon allergen exposure, such as after ingestion of peanut or tree nuts. ${ }^{9}$ The release of mediators such as histamine, leukotrienes, and prostaglandins result in pathophysiologic events including smooth muscle contraction, increased vascular permeability, vasodilation, and stimulation of the nervous system with reflex vagal activation. ${ }^{14}$ These physiologic effects result in the classic symptoms of anaphylaxis, which include cutaneous and mucosal involvement in the form of urticaria and angioedema; respiratory symptoms such as cough, wheezing, or dyspnea; abdominal symptoms including vomiting, diarrhea, and uterine contractions; as well as hypotension; and in severe cases, hypovolemic shock. Gastrointestinal symptoms are more commonly observed in cases of foodinduced anaphylaxis compared with anaphylaxis from other causes. ${ }^{15}$ Features of anaphylaxis differ based upon age of the patient. ${ }^{16}$ Cardiovascular collapse is reported more often in adults, compared with hives, vomiting, wheezing, and stridor in children. ${ }^{17,18}$ Anaphylaxis in infants is more likely to be underdiagnosed due to atypical clinical presentations with nonspecific symptoms such as lethargy and irritability, as well as inability to subjectively report symptoms. ${ }^{19}$

In the case of nut-induced anaphylaxis, as with other foods, symptoms typically present within 5-30 minutes of ingestion. ${ }^{20}$ Biphasic reactions, in which return of anaphylactic symptoms occurs following an asymptomatic period of an hour or more after the initial reaction, without further exposure to antigen, can occur in 3\%-20\% of severe food reactions. ${ }^{9,21,22}$ However, the mechanism of biphasic anaphylaxis is largely unknown, and these late phase reactions have been observed in only $2 \%$ of anaphylaxis induced by foods during inpatient oral food challenges (OFCs). ${ }^{23}$ Biphasic reactions typically develop within 8 hours of resolution of the initial reaction, but may occur up to 72 hours later. ${ }^{24}$ Risk factors for late phase reactions may include delayed onset of initial symptoms (>30 minutes), $\beta$-blockade, administration delay or inadequate dose of epinephrine, as well as reaction to an ingested allergen (food), as opposed to an injected allergen. $^{22}$

Foods are the most common cause of anaphylaxis in the outpatient setting, representing up to half of all cases of anaphylaxis treated in emergency departments in the USA. ${ }^{25}$ Additionally, food triggers account for up to $50 \%-80 \%$ of anaphylactic reactions in children. ${ }^{9,11}$ Perhaps even more importantly, food allergens account for $30 \%$ of fatal cases of anaphylaxis with an estimated 100 deaths per year due to food-induced anaphylactic reactions. ${ }^{26,27}$ Risk factors for fatal food anaphylaxis include an allergy to peanuts or tree nuts, a history of asthma, and failure to administer epinephrine promptly. ${ }^{28}$ Adults are up to nine times more likely to develop severe peanut or tree-nut-allergic reactions than children. ${ }^{28}$ Adolescents and young adults are also at risk for life-threatening anaphylaxis, given risk-taking behavior and frequent underreporting of symptoms in these age groups.

\section{Diagnosis}

All patients with a history of clinical reaction to peanut or tree nuts should be referred to an allergist for further evaluation. OFC remains the gold standard for diagnosis of any food allergy but is not always used given the risk of severe anaphylactic reaction. ${ }^{23,29}$ More often, the diagnosis of peanut or tree nut allergy is based upon a convincing clinical history, positive testing via skin prick or serum food-specific $\mathrm{IgE}$, and rarely, if needed, confirmatory OFC. Specific IgE testing, either by skin prick or serum food-specific IgE, is not always sensitive or highly specific, ${ }^{30}$ especially in the absence of convincing clinical history of anaphylaxis to the food in question. It is also important to note that allergy testing correlates only with the risk of reactivity to foods but does not predict severity of future reactions. Intradermal skin testing to foods can induce severe reactions and should not be performed. Other diagnostic methods such as the atopy patch test remain controversial and are generally not recommended for the diagnosis of food allergy. ${ }^{31}$

For peanut specifically, there has been recent development in component testing for diagnosis. This includes serum-specific IgE for various peanut proteins such as Ara $\mathrm{h}$ $1,2,3$, and 8 . The clinical utility of component testing remains yet to be fully determined, but testing to these 
proteins in patients allergic to peanut has been shown to be more specific and may correlate with various clinical phenotypes. For example, IgE to Ara h 2 was shown to be more specific than testing to whole peanut IgE when confirmed by OFC. ${ }^{32}$ IgE to storage proteins, Ara h 1, 2, and 3, has been associated with severe allergic reactions, ${ }^{33}$ whereas Ara $h$ 8 seems to correlate with milder, oral-allergy symptoms, likely due to structural similarities to the major allergen in birch pollen. ${ }^{34}$

To verify acute anaphylaxis triggered by nuts or other foods, serum total tryptase level can be utilized, though may be less sensitive than in cases of drug or hymenopterainduced anaphylaxis. ${ }^{35}$ Tryptase is abundant in mast cell secretory granules and the levels immediately increase, peaking $\sim 1-2$ hours after onset of symptoms. Importance of obtaining a timely sample makes clinical utilization difficult. Ideally, a serum tryptase level should be obtained within 3 hours of symptom onset, as levels return to baseline within 24 hours of symptom resolution. ${ }^{36}$ In cases of food-induced anaphylaxis, however, often serum tryptase is not elevated, even when sent within an appropriate time frame. This may be due to the activity of mucosal mast cells and basophils involved in food-induced anaphylaxis, which contain less tryptase compared with cutaneous mast cells that are more frequently activated in other causes of anaphylaxis, such as drugs or hymenoptera. ${ }^{35,37-39}$

Other laboratory markers that have been studied in anaphylaxis include serum histamine, urinary histamine metabolites, and concentration of angiotensin-converting enzyme (ACE). ACE is an enzyme involved in bradykinin catabolism, and angioedema is a known side effect for up to $0.7 \%$ of patients taking ACE-inhibiting medications. ${ }^{40}$ Regarding ACE levels, one study of peanut- and tree-nut-allergic individuals found an increased risk of severe pharyngeal edema in those patients having ACE concentrations in the lowest quartile $(<37.0 \mathrm{mmol} / \mathrm{L}) .{ }^{28}$ Serum histamine is a less practical marker as it peaks within 10 minutes of anaphylaxis onset and returns to baseline values within 1 hour. Urinary histamine metabolites may be of better utility as these can remain elevated up to 24 hours following an episode of anaphylaxis; however, their utility in clinical practice is limited.

\section{Cross-reactivity between nuts}

Although clinical cross-reactivity between nuts may be difficult to establish, the possibility of exhibiting symptoms of food allergy to multiple nuts plays an important role in the management of patients allergic to nut, especially for children who are of an age where identification of individual nuts is incomprehensible. The summary of nut cross-reactivity is given in Table 1. It is common to find positive testing (skin prick or serum-specific IgE) to other legumes in those patients with history of clinical reaction to peanut. A study of 62 children with legume allergy found $79 \%$ of patients with serologic evidence of IgE binding to at least one additional legume and $37 \%$ had $\operatorname{IgE}$ binding to all six legumes tested, including peanut, soybean, lima bean, pea, garbanzo bean, and green beans. ${ }^{41,42}$ Despite this common finding of cross-sensitization, the rate of clinical allergy to multiple legumes is much lower. This has been demonstrated in multiple studies of children with peanut allergy, in which double-blind, placebo-controlled OFCs were used to assess clinical reactivity to soy. ${ }^{43,44}$ Although a good proportion (up to $31 \%$ ) of patients allergic to peanut exhibited a positive skin test result to soy, significantly fewer children had clinical reactivity to both legumes (only 1\%-3\%). Another study of children with atopic dermatitis showed no reaction to any other legumes tested in children sensitive (skin test positive) to peanut. ${ }^{43}$

Co-sensitization between peanut and tree nuts is common; however only one-third of patients with peanut allergy also exhibit clinical allergy to one or more tree nuts. ${ }^{31}$ For example,

Table I Nut cross-reactivity

\begin{tabular}{ll}
\hline Food allergen & Potential clinical cross-reactivity \\
\hline Peanut & Legumes (soy, lentils, chickpeas) \\
& High rate of cross-sensitization, but clinical cross- \\
reactivity uncommon (5\%) & Multiple legume allergy may be associated with \\
sensitization to lentil and chickpea & Tree nuts \\
& Approximately one-third of patients with peanut \\
& allergy report clinical reactivity to tree nuts (not \\
& evaluated by DBPCFC) \\
Significant cross-reactivity between peanut and \\
certain tree nut epitopes (almond, walnut, pecan, \\
hazelnut, Brazil nut) \\
Seeds \\
Co-sensitization is common, but clinical cross- \\
reactivity unknown \\
Other tree nuts \\
Clinical reactivity to multiple tree nuts reported in \\
up to one-third of patients (37\%) \\
Seeds \\
Co-sensitization is common, but clinical cross- \\
reactivity unknown \\
Peanut (see above) \\
Pecan - clinical cross-reactivity \\
Pistachio - clinical cross-reactivity \\
Tree nuts
\end{tabular}

Note: Data from Sampson et al, ${ }^{31}$ and Sicherer. ${ }^{85}$

Abbreviation: DBPCFC, double-blind placebo-controlled food challenge. 
one study in the UK found $59 \%$ of peanut-sensitized patients were also sensitized to hazelnut, Brazil nut, or both. ${ }^{45}$ Other studies have found limited serologic cross-reactivity between peanut and tree nuts. ${ }^{46}$ For patients with an allergy to peanut, it is important to consider age, risk of cross-contamination, and implications of dietary restrictions before recommending a peanut versus completely nut-free diet.

Similarly, patients allergic to tree nut frequently exhibit sensitization to other tree nuts. In particular, associations between certain nuts, for example, cashew-pistachio and walnut-pecan, are particularly strong. Clinical crossreactivity to multiple nuts has been reported in up to one-third of patients evaluated for tree nut allergy. ${ }^{47,48}$ In general, only foods that have elicited reactions should be avoided, and in tree-nut-allergic individuals, previously tolerated individual tree nuts that were negative in skin test can likely be continued. In special circumstances, such as for young children, it is not uncommon to suggest avoidance of all tree nuts as to avoid accidental exposure. Individual tree nuts that have not yet been introduced can be done so by OFC in the office, if necessary. Again, this decision should be made based on clinical history, risk of cross-contamination, age of the patient, and test results.

\section{Management Dietary avoidance}

Strict dietary avoidance of peanut and/or tree nuts remains the mainstay of treatment for nut-allergic individuals. Dietary avoidance has become somewhat easier to follow with standardized labeling of the eight most common food allergens (peanut, tree nuts, milk, egg, soy, wheat, fish, and shellfish) on most packaged foods in the USA since 2006. However, advisory labeling can become confusing for patients when phrases such as "may contain" and "processed in a facility" are used. These types of precautionary labels are not standardized and therefore not all products with potential for cross-contamination are similarly identified. At times, patients allergic to peanut and tree nut are able to tolerate various products labeled with these discretionary phrases, but not others labeled with similar statements.

\section{Education and special settings}

In general, efforts of patients allergic to nuts to control avoidance at home can be quite successful, though there are certain circumstances and situations that remain high risk for cross-contamination and accidental exposure. Most cases of nut anaphylaxis in children do occur in the home, but this includes first reactions to peanut, with $76 \%$ occurring at home. ${ }^{18,21,49}$ Particularly in nut allergy, reactions outside the home tend to be more severe and are more likely to be treated with epinephrine. ${ }^{50}$ Of children who have already been diagnosed with peanut allergy, accidental exposures occur at an annual incidence rate of only $\sim 14.3 \%,{ }^{51}$ less frequently than previously reported, but up to $20 \%$ of children with a known food allergy (not specific to nuts) will develop a reaction at school at some point. In addition to school or day care, children's parties, restaurants, and bakeries are also high risk for cross-contamination and accidental exposure. ${ }^{50}$ For these reasons, the education of patients and parents regarding high-risk situations is of great importance. When available, utilizing a registered dietician may be especially helpful. Printed information is also useful for patients and parents not only to read for themselves, but also to distribute to other caregivers. Encouraging children not to accept food from strangers, or to check with a parent or trusted caregiver about unknown or unlabeled foods helps them take ownership of their food allergy and will bring attention to adults who may be unaware of specific dietary restrictions.

Within a comprehensive plan for the child with nut allergy, it is important to include all caregivers as studies have demonstrated deficiencies in symptom recognition, particularly in schools. ${ }^{52}$ Most peanut and tree nut reactions at school occur in the classroom and are due to utilization of nuts in craft projects or nut exposure during celebrations such as for a birthday. Other settings for potential food reactions include the playground or off-site field trips, when there may be less direct supervision or less opportunity to control for potential exposures..$^{50,52}$ A medical identification bracelet or necklace can be helpful in these circumstances, in order to easily identify food allergies to those unfamiliar with the patient.

Of all patients with a known peanut allergy, 60\% will have an accidental peanut exposure within 5 years. ${ }^{20,53,54}$ In contrast to children, food reactions in adults more commonly occur in restaurants, followed by home, workplace, or school. ${ }^{55,56}$ Specifically for nuts, commercial catering is an additional risk factor, accounting for $68 \%$ of reactions. ${ }^{57}$ Anaphylaxis to inhaled food allergens has been reported, mostly for seafood, when vapors during cooking become carriers for airborne protein allowing physical contact of protein with mucous membranes. Peanut has also been reported to cause allergic reactions via inhalation, though most studies are based on self-reported symptoms and have not been positively confirmed with inhalation challenge. ${ }^{58}$ In fact, casual contact of peanut butter has been studied in peanut-sensitized children and neither intact skin exposure 
nor inhalation was shown to elicit systemic or respiratory reactions. ${ }^{59}$ This point becomes important when counseling patients and parents about potential exposures such as the school lunchroom or on airplanes.

Of food reactions in restaurants, most occur in Asian establishments and in ice-cream parlors or bakeries, with desserts as a common meal. ${ }^{60}$ Asian restaurants can be particularly problematic for patients allergic to nuts as the use of nuts and seeds in cooking tend to be more common, along with utilization of pans for multiple meal preparations (risk for cross-contamination). It is important for patients to notify the staff of the restaurant about their nut allergy, as in most cases of food reactions in restaurants, this has not been done. Specifically for nut allergy, it has been stated that someone in the establishment would have known nut was an ingredient, if attention was called to the allergy. Staff surveys have indicated a false sense of security with $25 \%$ believing that removing an allergen from a finished meal or consuming only a small amount of allergen is safe. Additionally, $35 \%$ believed that fryer heat would destroy allergens, and half of staff surveyed considered a buffet safe so long as it was kept clean. ${ }^{61}$

Nut oils are sometimes used for cooking and preparing food in various restaurants, such as fried items in fast-food restaurants, and may provide a potential source for allergen exposure. In general, nut oils when highly refined are tolerated in patients allergic to nuts. However, due to varied standards in the refining processes, there remains some risk for reaction when allergic individuals consume nut oils, especially crude oil. Gourmet-style peanut oil, however, is cold-pressed and contains a significant amount of protein. Peanut oil specifically has been studied via double-blind oral challenge in peanut-allergic individuals and found to be safe when refined, while crude peanut oil did elicit some clinical reactions. Due to potential variations in protein content between different preparations, it is generally recommended to avoid foods containing peanut oil. ${ }^{62,63}$

When reviewing anticipatory guidance for possible reactions, education regarding potential for future severe reactions despite severity of previous reactions is also extremely important. A common misconception is that severity of past reactions will predict future outcomes. ${ }^{64}$ For example, if a child developed hives upon his first reaction to peanut, the parents may assume each additional exposure will only elicit hives, and the condition is (inappropriately) thought of as a "mild allergy". The provider should discuss that regardless of previous symptoms, any future accidental ingestion may result in a severe, life-threatening reactions. One study from
2005 used double-blind, placebo-controlled food challenges in patients allergic to peanuts and found poor correlation between severity of reported reactions and reactions elicited in the challenge. Furthermore, only the most recent community reaction predicted severity of challenge-based reactions, but even this association was weak. ${ }^{64}$

\section{Treatment of anaphylactic reactions}

The USA, European, and international guidelines (World Allergy Organization [WAO]) all recommend epinephrine as the drug of choice for all causes of anaphylaxis including food-induced anaphylaxis. ${ }^{65}$ The appropriate dose should be promptly administered upon onset of symptoms. Failure to receive epinephrine in a timely manner is a risk factor for fatality due to anaphylaxis, and studies have demonstrated that epinephrine is administered in only $25 \%-44 \%$ of patients with anaphylactic reactions. ${ }^{55,56,66}$ Additional therapies for anaphylactic reactions include supplemental oxygen and volume repletion for hypotension when appropriate. Symptom-specific adjunctive therapies may also be considered. These would include bronchodilators for wheezing and H1-antihistamines for pruritus, cutaneous symptoms, or rhinorrhea. Systemic corticosteroids in the acute management of anaphylaxis have been shown to be of questionable value, though they are routinely used as a second-line agent for possible prevention of late-phase reactions. ${ }^{67}$

All patients and parents of patients allergic to peanut or tree nut should be educated about the signs and symptoms of anaphylaxis. The treatment of choice for food-related anaphylaxis is injectable epinephrine in the lateral thigh. Currently, two doses of epinephrine autoinjectors are available. It is suggested that the $0.15 \mathrm{mg}$ dose epinephrine autoinjector be prescribed for children weighing $10-25 \mathrm{~kg}$ (22-55 lb) and an autoinjector with $0.30 \mathrm{mg}$ of epinephrine for those weighing $\geq 25 \mathrm{~kg}$ (55 lb). ${ }^{68}$ The correct use of an epinephrine autoinjector, including return demonstration, should be reviewed not only upon initial evaluation, but also at least on a yearly basis. This yearly instruction is important as it has been shown that many patients do not properly use epinephrine autoinjectors or forget how to use them after as little as a few months. ${ }^{69}$ Patients should be provided with written instructions including an action plan, which details signs and symptoms of anaphylaxis and indications for the use of emergency medications, including epinephrine. It is also important to review the proper storage of self-injectable epinephrine away from temperature extremes in order to protect the drug from degradation. Many preparations of self-injectable epinephrine now come equipped with a second 
dose, which may be required for refractory or severe anaphylactic reactions. For these reasons, it has been recommended that both doses of injectable epinephrine be kept together and not split between environments (school/home). A second dose of epinephrine should be administered if anaphylactic symptoms persist beyond 10 minutes, as 12\%-19\% of foodinduced anaphylactic reactions require more than one dose of epinephrine. ${ }^{12,18,55,56,70}$

\section{Future directions Immunotherapy for foods}

Allergen immunotherapy is a procedure that involves administration of an allergen on a regular basis with the intention to promote specific immune mechanisms and ultimately promote clinical tolerance to the allergen. For foods, several methods of immunotherapy have been studied including oral, sublingual, epicutaneous (patch), and subcutaneous. Subcutaneous immunotherapy for peanut has proven impractical due to risk of developing systemic allergic reaction. ${ }^{71}$ Out of all methods, OIT for nuts may be the most promising. A number of exciting studies are emerging, though long-term outcomes need to be further evaluated before this therapy is readily accepted for clinical practice. Furthermore, questions remain unanswered regarding whether protocols promote desensitization or tolerance. Desensitization is a temporary and reversible state, meaning once administration of the allergen is suspended, clinical reactivity returns. Tolerance refers to a long-term effect of unresponsiveness to the allergen.

In 2005, Enrique et al from Spain performed a randomized, double-blind placebo-controlled study for sublingual immunotherapy (SLIT) in adults with hazelnut allergy. ${ }^{72}$ During the final assessment, half of the patients in the treatment group were able to reach the highest dose of hazelnut ( $20 \mathrm{~g}$ ) on OFC compared with only $9 \%$ in placebo group. Long-term efficacy was not evaluated.

While additional data on immunotherapy for tree nuts is somewhat lacking, peanut immunotherapy, specifically OIT, has emerged as a potential approach for induction of tolerance in allergic individuals. Recently, a few meta-analyses of immunotherapy for food have been published, including a Cochrane review specifically on peanut OIT. ${ }^{73}$ Overall, the analyses concluded that peanut OIT with short-term incremental doses of the allergen seems to be effective for inducing desensitization in some patients who are able to tolerate the regimen, but none of the studies showed induction of tolerance by OIT and no trials followed subjects for $>2$ years. ${ }^{74}$ One study published in 2014 demonstrated that $50 \%$ of subjects with peanut allergy treated with OIT for up to 5 years had sustained unresponsiveness for 4 weeks after cessation of therapy. ${ }^{75}$ Similar studies with patients followed for longer time periods after discontinuation of OIT are required to support this result. In all studies of OIT in food allergy, the rates of adverse reaction are not insignificant (up to 90\%) in the treatment groups. ${ }^{74}$ Most reactions are mild, but further studies are needed to adequately assess risk and safety before recommending this treatment in clinical practice. An additional alarming statistic reported in a recent meta-analysis includes the development of eosinophilic esophagitis in up to $2.7 \%$ of patients undergoing OIT. ${ }^{76}$ This further illustrates the need for additional long-term follow-up studies on OIT in food allergy.

Other recent studies have looked at SLIT for peanut allergy, which involves incremental doses of daily peanut protein placed under the tongue. ${ }^{77-79}$ In 2013 , Fleischer et al showed that after 44 weeks of therapy, $70 \%$ of subjects aged 12-40 years receiving peanut SLIT were able to tolerate a median successfully consumed dose of $5 \mathrm{~g}$ peanut protein (or tenfold more peanut powder than at baseline OFC) compared with only $15 \%$ of patients who received placebo. ${ }^{79}$ In 2015, Burks et al presented long-term follow-up of the same study cohort, after 2 and 3 years of peanut SLIT. Over $50 \%$ of participants discontinued therapy despite most adverse reactions being localized to the oropharynx. Of the peanut SLIT group, only $10.8 \%$ were fully desensitized to $10 \mathrm{~g}$ of peanut powder by the end of the 3 years, but all of those who were desensitized also achieved sustained unresponsiveness after discontinuation of SLIT for 8 weeks (as determined by an open feeding challenge with peanut butter). ${ }^{77}$ Another pilot study of peanut SLIT was published by Narisety et al in 2015. This was also a randomized, double-blind, placebocontrolled trial, but included peanut OIT as well. Twenty-one children were randomized to either receive active peanut SLIT/placebo OIT or placebo SLIT/active peanut OIT. Of the 16 children who did not discontinue therapy, all were able to tolerate over tenfold increase in their peanut challenge threshold, but this threshold was significantly greater in the active OIT group $(P=0.1)$. Adverse reactions were mild, but more common in the active OIT group. ${ }^{78}$ All of these peanut SLIT studies show promise in inducing both clinical desensitization and sustained unresponsiveness for peanut-allergic individuals, though adherence seems that it may be an issue and more long-term follow-up is needed to fully evaluate side efficacy and potential side effects.

The newest method in prevention of peanut allergy was presented at the American Academy of Asthma, Allergy and Immunology (AAAAI) annual conference in March, 2015. In 
a late breaking abstract, Hugh A. Sampson, MD, FAAAAI, revealed the results of a multinational, double-blind, placebocontrolled randomized trial of epicutaneous immunotherapy for peanut allergy. After 1 year of therapy, patients treated with the highest dose peanut patch $(250 \mu \mathrm{g})$ tolerated ten times the dose at their entry oral peanut challenge (at least $1 \mathrm{~g}$ of peanut protein or approximately four peanuts). Compliance was also promising at $95 \%$, and there were no serious adverse reactions related to the therapy. ${ }^{80}$

\section{Prevention}

Numerous studies have looked into maternal diet and early infant feeding patterns in the development of food allergy. Currently, there is a lack of sufficient evidence to support specific dietary recommendations in either the mother or child in regards to prevention of peanut and tree nut allergy. ${ }^{81}$ It has been observed that prevalence of peanut allergy in children of similar ancestry is lower in countries that introduce peanut at an earlier age. ${ }^{82}$ There has been recent attention to one particular study assessing efficacy of peanut consumption during infancy for preventing peanut allergy in high-risk infants. The Learning Early About Peanut (LEAP) enrolled over 600 infants who had increased risk of peanut allergy due to either severe eczema, egg allergy, or both. ${ }^{83}$ Participants were randomized to either consume or avoid peanuts and followed until 60 months of age. Of the 530 infants with negative initial skin prick to peanut, prevalence of peanut allergy at 60 months was reduced by $86 \%$ in the consumption group compared with the avoidance group. In the 98 children with initial positive skin prick testing to peanut, prevalence of peanut allergy was reduced by $70 \%$ in the consumption group compared with avoidance. These dramatic results may change the recommendations we have for infant feeding practices in the future and interim recommendations have already been released, ${ }^{84}$ but it is important to note that though this was a high-risk population, it excluded children who were already allergic to peanut. The current recommendation for all children allergic to peanut is to continue with strict dietary avoidance.

\section{Conclusion}

Over the past decade, peanut and tree nut allergies have become more prevalent in Westernized countries. Management of reactions is important given nut allergy in itself is a risk for fatal anaphylaxis. Current management for those with nut allergies includes strict dietary avoidance and treatment of systemic reactions with injectable epinephrine. Dietary avoidance can be quite difficult, especially for young children and in special situations such as restaurants, where risk of cross-contamination remains quite high. Labeling of processed foods and awareness in the community regarding nut allergy have helped make dietary avoidance somewhat easier, though there remains much room for improvement in education and awareness. Given the effect food allergy has on quality of life, it is not surprising that much attention has gone into discovering alternative and more definitive treatments for those with peanut and tree nut allergy. One of those treatments, OIT for peanut, has shown promising results in clinical trials but is not yet ready for application to general clinical practice. ${ }^{74}$

\section{Disclosure}

The authors report no conflicts of interest in this work.

\section{References}

1. King JC, Blumberg J, Ingwersen L, Jenab M, Tucker KL. Tree nuts and peanuts as components of a healthy diet. J Nutr. 2008;138: 1736S-1740S.

2. Bewley J, Black M, Halmer P. The encyclopedia of seeds: science, technology and uses. Ann Bot. 2006;100(6):1379.

3. Rosengarten FJ. The Book of Edible Nuts. Mineola (NY): Dover Publications; 2004.

4. Ferdman RA. The rise of the American almond craze in one nutty chart. The Washington Post. August 6, 2014.

5. UUSDoAER. Food Availability (Per Capita) Data System. 2014. Available from: http://www.ers.usda.gov/data-products/food-availability(per-capita)-data-system.aspx. Accessed May 10, 2015.

6. Sicherer SH, Munoz-Furlong A, Godbold JH, Sampson HA. US prevalence of self-reported peanut, tree nut, and sesame allergy: 11-year follow-up. J Allergy Clin Immunol. 2010;125:1322-1326.

7. Sicherer SH. Epidemiology of food allergy. J Allergy Clin Immunol. 2011;127:594-602.

8. Wood RA, Sampson HA. Oral immunotherapy for the treatment of peanut allergy: is it ready for prime time? J Allergy Clin Immunol Pract. 2014;2:97-98.

9. Lieberman P, Nicklas RA, Oppenheimer $J$, et al. The diagnosis and management of anaphylaxis practice parameter: 2010 update. J Allergy Clin Immunol. 2010;126:.e1-.e42.

10. Simons FE, Sheikh A. Evidence-based management of anaphylaxis. Allergy. 2007;62:827-829.

11. Colver AF, Nevantaus H, Macdougall CF, Cant AJ. Severe food-allergic reactions in children across the UK and Ireland, 1998-2000. Acta Paediatr. 2005;94:689-695.

12. Jarvinen KM, Sicherer SH, Sampson HA, Nowak-Wegrzyn A. Use of multiple doses of epinephrine in food-induced anaphylaxis in children. J Allergy Clin Immunol. 2008;122:133-138.

13. Sampson HA, Munoz-Furlong A, Campbell RL, et al. Second symposium on the definition and management of anaphylaxis: summary report - second National Institute of Allergy and Infectious Disease/ Food Allergy and Anaphylaxis Network symposium. J Allergy Clin Immunol. 2006;117:391-397.

14. Adkinson N, Busse W, Bochner B, Holgate S, Middleton E, editors. Middleton's allergy. Principles and Practice. 7th ed. St Louis, MO: Mosby; 2009:1027-1038.

15. Cianferoni A, Novembre E, Mugnaini L, et al. Clinical features of acute anaphylaxis in patients admitted to a university hospital: an 11-year retrospective review (1985-1996). Ann Allergy Asthma Immunol. 2001;87:27-32. 
16. Braganza SC, Acworth JP, McKinnon DR, Peake JE, Brown AF. Paediatric emergency department anaphylaxis: different patterns from adults. Arch Dis Child. 2006;91:159-163.

17. Rudders SA, Banerji A, Clark S, Camargo CA Jr. Age-related differences in the clinical presentation of food-induced anaphylaxis. J Pediatr. 2011;158:326-328.

18. Uguz A, Lack G, Pumphrey R, et al. Allergic reactions in the community: a questionnaire survey of members of the anaphylaxis campaign. Clin Exp Allergy. 2005;35:746-750.

19. Simons FE. Anaphylaxis in infants: can recognition and management be improved? J Allergy Clin Immunol. 2007;120:537-540.

20. Sicherer SH, Furlong TJ, Munoz-Furlong A, Burks AW, Sampson HA. A voluntary registry for peanut and tree nut allergy: characteristics of the first 5149 registrants. J Allergy Clin Immunol. 2001;108: $128-132$.

21. Lee JM, Greenes DS. Biphasic anaphylactic reactions in pediatrics. Pediatrics. 2000;106:762-766.

22. Tole JW, Lieberman P. Biphasic anaphylaxis: review of incidence, clinical predictors, and observation recommendations. Immunol Allergy Clin North Am. 2007;27:309-326, viii.

23. Jarvinen KM, Amalanayagam S, Shreffler WG, et al. Epinephrine treatment is infrequent and biphasic reactions are rare in food-induced reactions during oral food challenges in children. J Allergy Clin Immunol. 2009; $124: 1267-1272$.

24. Lieberman P. Biphasic anaphylactic reactions. Ann Allergy Asthma Immunol. 2005;95:217-226.

25. Keet CA, Wood RA. Food allergy and anaphylaxis. Immunol Allergy Clin North Am. 2007;27:193-212, vi.

26. Sampson HA. Anaphylaxis and emergency treatment. Pediatrics. 2003;111:1601-1608.

27. Burks AW, Tang M, Sicherer S, et al. ICON: food allergy. J Allergy Clin Immunol. 2012;129:906-920.

28. Summers CW, Pumphrey RS, Woods CN, McDowell G, Pemberton PW, Arkwright PD. Factors predicting anaphylaxis to peanuts and tree nuts in patients referred to a specialist center. J Allergy Clin Immunol. 2008;121(632-638):e632.

29. Perry TT, Matsui EC, Conover-Walker MK, Wood RA. Risk of oral food challenges. J Allergy Clin Immunol. 2004;114:1164-1168.

30. Lemon-Mule H, Nowak-Wegrzyn A, Berin C, Knight AK. Pathophysiology of food-induced anaphylaxis. Curr Allergy Asthma Rep. 2008;8:201-208.

31. Sampson HA, Aceves S, Bock SA, et al. Food allergy: a practice parameter update-2014. J Allergy Clin Immunol. 2014;134(1016-1025):e1043.

32. Lieberman JA, Glaumann S, Batelson S, Borres MP, Sampson HA, Nilsson C. The utility of peanut components in the diagnosis of IgEmediated peanut allergy among distinct populations. J Allergy Clin Immunol Pract. 2013;1:75-82.

33. Nicolaou N, Murray C, Belgrave D, Poorafshar M, Simpson A, Custovic A. Quantification of specific IgE to whole peanut extract and peanut components in prediction of peanut allergy. J Allergy Clin Immunol. 2011;127:684-685.

34. Asarnoj A, Nilsson C, Lidholm J, et al. Peanut component Ara h 8 sensitization and tolerance to peanut. JAllergy Clin Immunol. 2012;130: 468-472.

35. Wongkaewpothong P, Pacharn P, Sripramong C, et al. The utility of serum tryptase in the diagnosis of food-induced anaphylaxis. Allergy Asthma Immunol Res. 2014;6:304-309.

36. Simons FE, Frew AJ, Ansotegui IJ, et al. Risk assessment in anaphylaxis: current and future approaches. J Allergy Clin Immunol. 2007;120:S2-S24.

37. Sampson HA, Jolie PL. Increased plasma histamine concentrations after food challenges in children with atopic dermatitis. $N$ Engl J Med. 1984;311:372-376

38. Sampson HA, Mendelson L, Rosen JP. Fatal and near-fatal anaphylactic reactions to food in children and adolescents. $N$ Engl J Med. 1992;327:380-384.
39. Schwartz LB, Irani AM, Roller K, Castells MC, Schechter NM. Quantitation of histamine, tryptase, and chymase in dispersed human T and TC mast cells. J Immunol. 1987;138:2611-2615.

40. Slater EE, Merrill DD, Guess HA, et al. Clinical profile of angioedema associated with angiotensin converting-enzyme inhibition. JAMA. 1988;260:967-970.

41. Bernhisel-Broadbent J, Taylor S, Sampson HA. Cross-allergenicity in the legume botanical family in children with food hypersensitivity. II. Laboratory correlates. J Allergy Clin Immunol. 1989;84:701-709.

42. Bernhisel-Broadbent J, Sampson HA. Cross-allergenicity in the legume botanical family in children with food hypersensitivity. J Allergy Clin Immunol. 1989;83:435-440.

43. Bock SA, Atkins FM. The natural history of peanut allergy. J Allergy Clin Immunol. 1989;83:900-904.

44. Sampson HA, McCaskill CC. Food hypersensitivity and atopic dermatitis: evaluation of 113 patients. J Pediatr. 1985;107:669-675.

45. Pumphrey RS, Wilson PB, Faragher EB, Edwards SR. Specific immunoglobulin E to peanut, hazelnut and brazil nut in 731 patients: similar patterns found at all ages. Clin Exp Allergy. 1999;29:1256-1259.

46. Goetz DW, Whisman BA, Goetz AD. Cross-reactivity among edible nuts: double immunodiffusion, crossed immunoelectrophoresis, and human specific igE serologic surveys. Ann Allergy Asthma Immunol. 2005;95:45-52.

47. Ewan PW. Clinical study of peanut and nut allergy in 62 consecutive patients: new features and associations. BMJ. 1996;312:1074-1078.

48. Sicherer SH, Burks AW, Sampson HA. Clinical features of acute allergic reactions to peanut and tree nuts in children. Pediatrics. 1998;102:e6.

49. Novembre E, Cianferoni A, Bernardini R, et al. Anaphylaxis in children: clinical and allergologic features. Pediatrics. 1998;101:E8.

50. Sicherer SH, Furlong TJ, DeSimone J, Sampson HA. The US peanut and tree nut allergy registry: characteristics of reactions in schools and day care. J Pediatr. 2001;138:560-565.

51. Yu JW, Kagan R, Verreault N, et al. Accidental ingestions in children with peanut allergy. J Allergy Clin Immunol. 2006;118:466-472.

52. Young MC, Munoz-Furlong A, Sicherer SH. Management of food allergies in schools: a perspective for allergists. J Allergy Clin Immunol. 2009; $124:$ e171-e174.

53. Nowak-Wegrzyn A, Conover-Walker MK, Wood RA. Food-allergic reactions in schools and preschools. Arch Pediatr Adolesc Med. 2001;155:790-795.

54. Vander Leek TK, Liu AH, Stefanski K, Blacker B, Bock SA. The natural history of peanut allergy in young children and its association with serum peanut-specific IgE. J Pediatr. 2000;137:749-755.

55. Banerji A, Rudders SA, Corel B, Garth AM, Clark S, Camargo CA Jr. Repeat epinephrine treatments for food-related allergic reactions that present to the emergency department. Allergy Asthma Proc. 2010;31: 308-316.

56. Rudders SA, Banerji A, Vassallo MF, Clark S, Camargo CA Jr. Trends in pediatric emergency department visits for food-induced anaphylaxis. J Allergy Clin Immunol. 2010;126:385-388.

57. Pumphrey R. Anaphylaxis: can we tell who is at risk of a fatal reaction? Curr Opin Allergy Clin Immunol. 2004;4:285-290.

58. Leonardi S, Pecoraro R, Filippelli M, et al. Allergic reactions to foods by inhalation in children. Allergy Asthma Proc. 2014;35:288-294.

59. Simonte SJ, Ma S, Mofidi S, Sicherer SH. Relevance of casual contact with peanut butter in children with peanut allergy. J Allergy Clin Immunol. 2003;112:180-182.

60. Furlong TJ, DeSimone J, Sicherer SH. Peanut and tree nut allergic reactions in restaurants and other food establishments. J Allergy Clin Immunol. 2001;108:867-870.

61. Ahuja R, Sicherer SH. Food-allergy management from the perspective of restaurant and food establishment personnel. Ann Allergy Asthma Immunol. 2007;98:344-348.

62. Taylor SL, Busse WW, Sachs MI, Parker JL, Yunginger JW. Peanut oil is not allergenic to peanut-sensitive individuals. J Allergy Clin Immunol. 1981;68:372-375. 
63. Hourihane JO, Bedwani SJ, Dean TP, Warner JO. Randomised, double blind, crossover challenge study of allergenicity of peanut oils in subjects allergic to peanuts. BMJ. 1997;314:1084-1088.

64. Hourihane JO, Grimshaw KE, Lewis SA, et al. Does severity of lowdose, double-blind, placebo-controlled food challenges reflect severity of allergic reactions to peanut in the community? Clin Exp Allergy. 2005;35:1227-1233.

65. Sampson HA, Munoz-Furlong A, Campbell RL, et al. Second symposium on the definition and management of anaphylaxis: summary report - second National Institute of Allergy and Infectious Disease/ Food Allergy and Anaphylaxis Network symposium. Ann Emerg Med. 2006;47:373-380.

66. Clark S, Bock SA, Gaeta TJ; Multicenter Airway Research Collaboration, 8 Investigators, et al. Multicenter study of emergency department visits for food allergies. J Allergy Clin Immunol. 2004;113:347-352.

67. Sheikh A. Glucocorticosteroids for the treatment and prevention of anaphylaxis. Curr Opin Allergy Clin Immunol. 2013;13:263-267.

68. Sicherer SH, Simons FE; Section on Allergy and Immunology, American Academy of Pediatrics. Self-injectable epinephrine for firstaid management of anaphylaxis. Pediatrics. 2007;119:638-646.

69. Bonds RS, Asawa A, Ghazi AI. Misuse of medical devices: a persistent problem in self-management of asthma and allergic disease. Ann Allergy Asthma Immunol. 2015;114(74-76):e72.

70. Oren E, Banerji A, Clark S, Camargo CA Jr. Food-induced anaphylaxis and repeated epinephrine treatments. Ann Allergy Asthma Immunol. 2007;99:429-432.

71. Nelson HS, Lahr J, Rule R, Bock A, Leung D. Treatment of anaphylactic sensitivity to peanuts by immunotherapy with injections of aqueous peanut extract. J Allergy Clin Immunol. 1997;99:744-751.

72. Enrique E, Pineda F, Malek T, et al. Sublingual immunotherapy for hazelnut food allergy: a randomized, double-blind, placebo-controlled study with a standardized hazelnut extract. J Allergy Clin Immunol. 2005;116:1073-1079.

73. Nurmatov U, Venderbosch I, Devereux G, Simons FE, Sheikh A. Allergen-specific oral immunotherapy for peanut allergy. Cochrane Database Syst Rev. 2012;9:CD009014.

74. Sampson HA. Peanut oral immunotherapy: is it ready for clinical practice? J Allergy Clin Immunol Pract. 2013;1:15-21.
75. Still LM, Jones SM. Sustained unresponsiveness to peanut in subjects who have completed peanut oral immunotherapy. Pediatrics. 2014; 134(Suppl 3):S155.

76. Lucendo AJ, Arias A, Tenias JM. Relation between eosinophilic esophagitis and oral immunotherapy for food allergy: a systematic review with meta-analysis. Ann Allergy Asthma Immunol. 2014;113: 624-629.

77. Burks AW, Wood RA, Jones SM, et al. Sublingual immunotherapy for peanut allergy: long-term follow-up of a randomized multicenter trial. J Allergy Clin Immunol. 2015;135(1240-1248):e1243.

78. Narisety SD, Frischmeyer-Guerrerio PA, Keet CA, et al. A randomized, double-blind, placebo-controlled pilot study of sublingual versus oral immunotherapy for the treatment of peanut allergy. J Allergy Clin Immunol. 2015;135(1275-1282):e1276.

79. Fleischer DM, Burks AW, Vickery BP, et al. Sublingual immunotherapy for peanut allergy: a randomized, double-blind, placebo-controlled multicenter trial. J Allergy Clin Immunol. 2013;131(119-127):e111-e117.

80. Hugh AS, Wence A, Claude T, et al. Epicutaneous immunotherapy (EPIT) is effective and safe to treat peanut allergy: a multi-national double-blind placebo-controlled randomized phase IIb trial. J Allergy Clin Immunol. 2015;135:AB390.

81. Greer FR, Sicherer SH, Burks AW; American Academy of Pediatrics Committee on, N, American Academy of Pediatrics Section on, A, and Immunology. Effects of early nutritional interventions on the development of atopic disease in infants and children: the role of maternal dietary restriction, breastfeeding, timing of introduction of complementary foods, and hydrolyzed formulas. Pediatrics. 2008;121:183-191.

82. Du Toit G, Katz Y, Sasieni P, et al. Early consumption of peanuts in infancy is associated with a low prevalence of peanut allergy. J Allergy Clin Immunol. 2008;122:984-991.

83. Du Toit G, Roberts G, Sayre PH, et al. Randomized trial of peanut consumption in infants at risk for peanut allergy. $N$ Engl J Med. 2015;372:803-813.

84. Fleischer DM, Sicherer S, Greenhawt M, et al. Consensus communication on early peanut introduction and the prevention of peanut allergy in high-risk infants. Allergy Asthma Clin Immunol. 2015;11:23.

85. Sicherer SH. Clinical implications of cross-reactive food allergens. J Allergy Clin Immunol. 2001;108:881-890.
Journal of Asthma and Allergy

\section{Publish your work in this journal}

The Journal of Asthma and Allergy is an international, peer-reviewed open-access journal publishing original research, reports, editorials and commentaries on the following topics: Asthma; Pulmonary physiology; Asthma related clinical health; Clinical immunology and the immunological basis of disease; Pharmacological interventions and

\section{Dovepress}

new therapies. Issues of patient safety and quality of care will also be considered. The manuscript management system is completely online and includes a very quick and fair peer-review system, which is all easy to use. Visit http://www.dovepress.com/testimonials.php to read real quotes from published authors. 